\title{
Türkiye Ekonomisine Kaldoryan Bakış (1980-2020)
}

\section{A Kaldorian Perspective on the Turkish Economy (1980-2020)}

\author{
Gülbahar ATASEVER ${ }^{1}$ ()
}

\section{Öz}

Uluslararası karşılaştırmalarda kullanılan en temel göstergeler enflasyon oranı, işsizlik oranı, ekonomik büyüme oranı ve cari işlemler dengesidir. Bu bağlamda söz konusu değişkenler, bir endeks çerçevesinde bir araya getirilerek ele alındığında, ülke bazında veya uluslararası karşılaştırmalarda pratik bir bakış açısı sağlamaktadır. Bu çalışmada değişkenler, ele alınan endeksler çerçevesinde ve ayrıca TOPSIS yöntemine göre analiz edilmiştir. 1980-2020 dönemi için söz konusu değişkenler bağlamında dar çekirdek, genişletilmiş çekirdek, Keynesyen, Boratav-Heterodoks endeks değerleri hesaplanarak Türkiye ekonomisinde yıllar ve dönemler bazında karşılaştırma yapılmıştır. Elde edilen sonuçlara göre; yıllar itibariyle endekslerdeki kırılımların birbirine çok benzer olduğu tespit edilmiştir. Bununla birlikte, endekslerin dönemsel makroekonomik performansı yorumlama konusunda birbirinden oldukça ayrıştıkları gözlemlenmiştir. Makroekonomik performans açısından en iyi dönem; Genişletilmiş Çekirdek ve Keynesyen endekslerde 1980-1989 dönemi iken, Boratav-Heterodoks endeksine göre 1990-1999 dönemi, Dar Çekirdek endeksine göre 2010-2020 dönemi, TOPSIS yöntemine göre ise, 20002009 dönemidir. Bu sonuç; beşeri sermaye, verimlilik, kurumlar ve nüfus gibi unsurların analiz dışında tutulmasından dolayı, ele alınan biçimiyle Kaldoryan bakış açısının dönemler arası etkinlik karşılaştırmalarında yetersiz olduğunu göstermektedir.

Anahtar kelimeler: Türkiye ekonomisi, Sihirli kare, Makroekonomik performans

\section{JEL Sınıflaması: E12, E17}

\section{ABSTRACT}

The most basic economic indicators used in international comparisons are inflation rate, unemployment rate, economic growth rate, and current account balance. In this context, when these variables are taken together within the framework of an index, they offer a practical perspective on a single country basis or in international comparisons. In this study, variables were analyzed using the TOPSIS method. During the 1980-2020 period, the narrow context of the aforementioned variables for the core, extended core, Keynesian, and heterodox Boratav year indices were calculated to make comparisons on the basis of time periods in the Turkish economy. The results obtained indicate that breakdowns in the indices by year are very

${ }^{1}$ Dr. Öğretim Üyesi, Muğla Sıtkı Koçman Üniversitesi, İktisadi ve İdari Bilimler Fakültesi, İktisat Bölümü, Muğla, Türkiye

ORCID: G.A. 0000-0001-7244-9243

Sorumlu yazar/Corresponding author: Gülbahar ATASEVER, Muğla Sıtkı Koçman Üniversitesi, İktisadi ve İdari Bilimler Fakültesi, İktisat Bölümü, Muğla, Türkiye E-posta/E-mail: gulbaharatasever@mu.edu.tr

Başvuru/Submitted: 02.03.2021

Revizyon Talebi/Revision Requested: 24.04.2021

Son Revizyon/Last Revision Received: 25.04.2021

Kabul/Accepted: 18.05 .2021

Atıf/Citation: Atasever, G. (2021). Türkiye ekonomisine kaldoryan bakış (1980-2020) istanbul iktisat Dergisi - Istanbul Journal of Economics, 71(1), 59-80. https://doi.org/10.26650/ISTJECON2021-886478 
similar; however, the indices differ considerably in interpreting periodic macroeconomic performance. Regarding the designated best period in terms of macroeconomic performance, while1980-1989 was the period in extended core and Keynesian indices, it was 1990-1999 according to the Boratav heterodox index, 2010-2020 according to the narrow core index, and 2000-2009 according to TOPSIS method. This result demonstrates that the
Kaldorian perspective is insufficient for efficiency comparisons between periods, as factors such as human capital, productivity, institutions, and populations are excluded from the analysis.

Keywords: Turkey economics, Magic square, Macroeconomic performance

JEL Classification: E12, E17

\section{EXTENDED ABSTRACT}

The most basic economic indicators used in international comparisons are inflation rate, unemployment rate, economic growth rate, and current account balance. In this context, when these variables are taken together within the framework of an index, they offer a practical perspective on a single country basis or in international comparisons. In this context, a composite indicator (dashboard) can be developed as a useful analytical tool. Policymakers, investors, and experts can monitor the performance of a country over the years by following these indices and make comparisons with other countries. The concept by which economic indicators are handled together is known as the "magic square" and is based on Kaldor's (1971) work. However, it should not be forgotten that a tradeoff exists between economic policy goals. The strong relationship of the past between economic growth and employment is no longer significant today. There may be situations wherein moderate growth rates increase unemployment. The existence of this trade-off relationship between goals can result in a compromise when approaching only one goal. Today, there is valid evidence that an inverse correlation occurs between unemployment and inflation in the short term and disappears in the long term (Paya, 2013, p. 56-57). An increase in economic growth rates may result in a deviation from the inflation target and create a current account deficit. Therefore, it does not seem possible to reach the targets determined simultaneously in terms of macroeconomic indicators.

In this study, Turkey's macroeconomic performance during the 1980-2020 period is examined in terms of growth, unemployment, inflation, and current 
account transactions involving variable balance (Benlialper, Cömert \& Düzçay, 2015) and indices are handled by further evaluation in the framework of the TOPSIS method. Variables in the context of narrow core, extended core, Keynesian, and heterodox index values calculated for Boratav period comparisons are made in relation to the Turkish economy. The narrow core index expresses equal weighting of unemployment, inflation, and growth rate, whereas the expanded core index includes equal weighting for the four variables, including current account balance. While the weight of unemployment and growth rate increased in the Keynesian index, the weight of the inflation rate decreased. In the Boratav heterodox index, since the inflation rate cannot be an indicator of welfare, inflation rate is excluded, and growth, unemployment, and current account balance are weighted equally.

The results obtained indicate that the breakdowns in the indices over the years are very similar. However, there was a lack of consensus on the periods of best or worst performance. The best performing period is marked as 2010-2020 according to the narrow core index, whereas the extended core and Keynesian indices specify 1980-1989, and the Boratav heterodox index points to 1990 1999. The TOPSIS method indicates $2000-2009$ as the period in which the best performance is observed. The worst performing period is 1990-1999, in terms of narrow core index, extended core index, and TOPSIS method, whereas the Keynesian index indicates 2000-2009 and the Boratav heterodox index indicates 2010-2020. The difference in the results is due to the differing weights of the variables in the indices. During the periods of Keynesian ideology, policies aimed at lowering unemployment rates will increase the favor of Keynesian and Boratav heterodox indices. Although the indices show a similar trend in terms of breakdowns, disagreement remains regarding the best or worst performance observed. The weighting of macroeconomic indicators included in these indices is effective in the emergence of this situation. Since the narrow core index does not include the current account balance GDP indicator, it marked 2010-2020, the period when current account balance was at its worst, as the period in which the best performance was observed. Conversely, the Boratav heterodox index calculates 2010-2020, when inflation is at its lowest, as the period when the worst performance is observed, since it does not include the inflation rate. 


\section{Giriş}

Hükümetlerin makroekonomik politikası genellikle büyüme, istihdam yaratma ve fiyat istikrarı olmak üzere üç hedefe bağlıdır. Günümüzde cari işlemler dengesi de bu hedeflere eklenmiştir. Büyüme, istihdam ve fiyat istikrarı "sihirli üçgen", bu üç göstergeye cari işlemler dengesi de eklenince "sihirli kare" olarak adlandırılmıştır. Ülkelerin bu hedeflere ulaşmak için oluşturdukları planlamaları ve her bir hedefe ilişkin performansları arasında önemli farklılıklar bulunmaktadır. Geleneksel olarak, bir ülkenin makroekonomik performansı, politika hedeflerinin ne ölçüde gerçekleştirildiği ile ölçülür (Chattopadhyay ve Bose, 2015, s. 51). Bu bağlamda geliştirilebilecek bileşik gösterge (dashboard) yararlı bir analiz aracıdır. Politika yapıcılar, yatırımcılar ve uzmanlar bu endeksleri takip ederek bir ülkenin yıllar içerisindeki performansını izleyebilir, diğer ülkelerle karşılaştırmalar yapabilir.

Kaldor'a (1971) göre hükümetlerin çoğu, II. Dünya Savaşı'nın ardından yüksek ve istikrarlı bir istihdam düzeyini sürdürmeye başladıktan sonra, ekonominin diğer önemli yönleriyle de ilgilenmeye başlamışlardır. Bu nedenle, tam istihdam politikasının uygulanabilmesi için, hükümetlerin sürdürülebilir bir ödemeler dengesi, yüksek bir büyüme oranı ve fiyatlar ile ücret istikrarını sağlayabilmesi gerekir. Dolayısıyla bu dört değişken, (ekonomik büyüme oranı, işsizlik, enflasyon ve ticaret dengesi), gelişmiş ülkelerin (ABD ve Euro Alanındakilerin) ve başlıca gelişmekte olan ekonomilerin (Brezilya, Rusya, Çin ve son sanayileşen Asya ülkeleri) performanslarının karşılaştııılmasında kullanılmaktadır (Firme ve Teixeira, 2014, s. 527). Kaldor'un önerdiği dört değişkeni ekonomik performansın ölçülmesinde ilk kullanan Almanya olmuştur. Savaşsonrası Alman ekonomi politikasının oluşturulmasında, 1967 İstikrar ve Büyüme Yasası önemli bir çıpadır. Bu yasa, ilgili tüm ekonomik politika yapııların politika kararları verirken makroekonomik dengeyi dikkate almalarını şart koşmaktadır. Makroekonomik dengeyi, "istikrarlı fiyat seviyesi", "yüksek istihdam seviyesi", "istikrarlı ve yeterli ekonomik büyüme" ve "dış ekonomik denge" gibi dört ekonomik hedefe aynı anda ulaşılması olarak tanımlar (Dullien, 2017, s. 7). 1966-1969 döneminde, ekonomi bakanı Karl Schiller ve maliye bakanı Franz J. Strauss, Kaldor'un önerdiği değişkenlerin kombinasyonunu, "Kaldor'un büyüsü" (ekonominin performansının 
karşılaştırılmasını ve görüntülenmesini basitleştiren bir kare) şeklinde göstermişlerdir (Firme ve Teixeira, 2014, s. 531).

Bununla birlikte, iktisat politika amaçları arasında bir ödünleşme ilişkisinin olduğu unutulmamalıdır. Geçmiş dönemlerdeki ekonomik büyüme ve istihdam arasındaki güçlü ilişki günümüzde pek anlamlı değildir. Ilımlı büyüme oranlarının işsizliği arttırdığı durumlar ortaya çıkabilmektedir. Hedefler arasında ödünleşme ilişkisinin varlığı, bir hedefe yaklaşırken başka bir hedeften taviz vermekle sonuçlanabilir. Günümüzde işsizlik ve enflasyon arasındaki ters korelasyonun kısa dönemde geçerli olduğu, uzun dönemde ise kaybolduğu yönünde kanıtlar vardır (Paya, 2013, s. 56-57). Ekonomik büyüme oranlarındaki artış, enflasyon hedefinden sapmaya ve cari açık yaratmaya neden olabilmektedir. Dolayısıyla, makroekonomik göstergeler açısından aynı anda belirlenen hedeflere ulaşılabilmesi mümkün görünmemektedir.

Türkiye ekonomisinde 1971-2003 dönemi gibi uzunca bir süre yüksek enflasyon; 1994 ekonomik krizi sırasında hiper enflasyon yaşanmıştır. 2004-2016 döneminde ise, 2008 küresel krizi hariç tek haneli enflasyon oranlarının görüldüğü, 2016 yılından itibaren ise yeniden çift haneli enflasyon oranlarına geri dönüldüğü söylenebilir. Türkiye, Kasım 2000 ve Şubat 2001 ekonomik krizlerinin ardından, 2002 yılından itibaren örtülü enflasyon hedeflemesine geçmiş, 2006 yılından itibaren ise, açık enflasyon hedeflemesi stratejisini uygulamaya devam etmiştir. Enflasyon hedeflemesiyle öngörülen \%5 enflasyon hedefinin hiçbir yıl boyunca sağlanamadığı görülmektedir. Türkiye'de enflasyonun belirleyicileri temel olarak para arzı, döviz kuru ve fiyatlar genel düzeyi arasındaki ilişkiler ile kamu harcamalarındaki artışa dayanmaktadır.

İşsizlik olgusu; ekonomik, toplumsal ve psikolojik temelli pek çok sorunun kaynağını oluşturmakta, karar vericilerin ve bir ülkede kurulu mekanizmaların çözüm üretmesi gereken asli bir konu olarak önem taşımaktadır. Pek çok makroekonomik değişkenden bahsedilse de nihai olarak bir ülkenin çözmesi gereken en büyük sorun işsizliktir. Özellikle 1980'li yıllardan itibaren küreselleşmenin içerdiği ve genişlettiği teknolojik yenilikler, eski işlerin yerini 
yenilerinin alması, beşeri sermaye yatırımlarına kaynak ayrılması konusunda büyük bir gereksinim yaratmıştır. Ekonomik ve siyasal kriz dönemleri, pandemi gibi dışsal şoklar, savaşlar gibi pek çok olağan dışı gelişmeler, iş kayıplarına neden olmakta, tıpkı fiyatlarda olduğu gibi işsizlik oranlarında da yapışkanlıklar üreten bir sistem yaratmaktadır. Ayrıca genç işsizlik oranı, işsizlik oranından oldukça farklı ayrışmakta (genel işsizlik oranının iki katı), beyin göçünü de beraberinde getirmektedir.

TÜiK verilerine göre, Türkiye'de işsizlik oranları yıllar içerisinde kademeli olarak artmıştır. Dönemler açısından incelenirse, 1960-1970 döneminde işsizlik oranlarının \%3-\%6 arasında dalgalandığı, 2000'li yıllara kadar ortalama işsizlik oranının \%7-\%8 bandında yer aldığı, 2000'li yıllardan itibaren ise çift hanelere ulaşarak \%10-\%13 arasında dalgalandığı görülmektedir. Genç işsizlik ise \%25-\%30 seviyelerine kadar tırmanmıştır. Bazı çalışmalar, yüksek büyüme oranlarının işsizlik oranlarını düşüreceği yönündeki Okun Kanununu desteklese de Okun katsayısının, konjonktürel dalgalanmalar çerçevesinde değişiklik gösterebileceği şeklinde sonuçlar üretmektedir (Attfield ve Silverstone, 1997; Daly ve Hobijn, 2010; Owyang ve Sekhposyan, 2012; Erdoğan, Yıldırım, Çevik ve Ünal, 2019). Diğer bir deyişle üretim, istihdam yaratmakta yetersiz kalmaktadır (istihdam yaratmayan büyüme kavramı).

Türkiye ekonomisi, 1980 yılından itibaren ihracata dönük sanayileşme stratejisi benimsemiş olup, uzun süreli makroekonomik istikrarsızlık nedeniyle göreli düşük büyüme oranları gerçekleşmiştir. Bu bağlamda, makro dengelerin zor tutturulabildiği bir ortamda, büyüme oranlarında yıldan yıla büyük dalgalanmalar oluşmuştur. Birbirini izleyen dönemlerde gerçekleşen farklı büyüme performansları, yatırım ve tüketim kararları üzerinde aşırı iyimser ya da aşırı kötümser beklentiler yaratarak var olan ekonomik istikrarsızlığı daha da şiddetlendirmiştir (Tarı ve Kumcu, 2005, s. 157). TÜiK verilerine göre, Türkiye'de 1980-2010 dönemi ortalama büyüme oranı \%4; 2010-2020 döneminde ise \%5 düzeyinde gerçekleşmiştir.

Türkiye'nin cari işlemler dengesi incelendiğinde, ekonomik kriz dönemlerinde cari açığın önceki yıllara göre düştüğü veya cari fazla verildiği; büyüme oranlarının 
yüksek olduğu dönemlerde ise cari açığın da büyümeye paralel olarak yükseldiği görülmektedir. Bu durum, Türkiye ekonomisinin büyüyebilmek için cari açık vermek zorunda olduğunu dolayısıyla, üretim yapısının ithal girdilere bağlı olduğunu göstermektedir. Ayrıca Türkiye'nin tasarruf oranlarının düşük düzeyde olması ve ithal ürünlere olan ilgisi de cari açığın tüketim cephesindeki belirleyenleridir. Literatürdeki çalışmalar Türkiye'de cari açık sorununu; bütçe açığı, aşırı değerli TL, toplam krediler, petrol fiyatları, ihracatın/ithalatı karşılama oranı, büyüme oranı gibi göstergelerle ilişkilendirmektedir (Erdoğan ve Bozkurt, 2009; Telatar, 2011; Bozgeyik ve Kutlu, 2019; Turan ve Afsal, 2020). Bu bağlamda sorunun kaynağı, üretim ve tüketim stratejileri olarak görülebilir. TÜiK verilerine göre, Türkiye'de cari işlemler dengesi, ekonomik büyümedeki artışa bağlı olarak 2010-2020 döneminde ortalama \%3,7 açık vermiştir. 1980-2010 döneminde cari açık \%1-\%3 aralığındadır. Cari işlemler dengesi, yatırım-tasarruf arasındaki dengenin sağlanıp sağlanmadığı konusunda da bilgi vermektedir. Cari işlemler dengesinin açık vermesi durumunda, yurt içi tasarrufların yatırımların finanse edilmesinde yetersiz kaldığı, bu nedenle yurt dışından sermaye girişine ihtiyaç duyulduğu anlaşılır. Yurt dışından sermaye girişinin sağlanabilmesi için ise yurt içi faiz oranlarının yükseltilmesi gereklidir.

Bu çalışmada, Türkiye'nin makroekonomik performansı 1980-2020 dönemi için büyüme, işsizlik, enflasyon ve cari işlemler dengesi değişkenlerini içeren (Benilalper ve ark., 2015) tarafından ele alınan endeksler ve ayrıca TOPSiS yöntemi çerçevesinde değerlendirilmiştir. Söz konusu değişkenler bağlamında dar çekirdek, genişletilmiş çekirdek, Keynesyen, Boratav-Heterodoks endeks değerleri hesaplanarak Türkiye ekonomisinde dönemler bazında karşılaştırma yapılmıştır. Çalışmaya sadece Türkiye'nin dahil edilmesi; beşeri sermaye, verimlilik, kurumlar ve nüfus gibi unsurların analiz dışında tutulması çalışmanın kısıtları arasında yer almaktadır.

\section{Literatür}

Ülkelerin makroekonomik performansının ölçülebilmesi için literatürde makroekonomik göstergelerin farklı kombinasyonlarının kullanıldığı görülmektedir. 
(Okun 1970), işsizlik ve enflasyon oranlarının toplamından oluşan iktisadi hoşnutsuzluk endeksini geliştirmiştir. (Kaldor 1971), enflasyon, işsizlik, büyüme oranları ile birlikte cari işlemler açığını ele almıştır. Calmfors ve Driffill (1988), işsizlik oranı ve cari işlemler açığının GSYH'a oranının toplamından oluşan "Calmfors Driffill Endeksi"ni geliştirmiştir. Melyn ve Moesen (1991), "Leuven Makroekonomik Performans Endeksi"ni geliştirmiştir. Burada, makroekonomik verilere normalleştirme işlemi uygulanmakta ve her ülke için politika ağırlıkları belirlenmektedir. Lovell, Pastor ve Turner (1995) GEM yaklaşımını geliştirerek 19 OECD ülkesinin 1970-1990 dönemine ilişkin makroekonomik performansını değerlendirmiştir. Moesen ve Cherchye (1998), makroekonomik performansın ölçümünde veri zarflama analizinden faydalanmıştır. Barro (1999), enflasyon, işsizlik, büyüme ve uzun dönemli faiz oranlarının bileşiminden oluşan "Sefalet Endeksi"ni geliştirmiştir. Cherchye (2001), belirli bir politikanın diğerlerine göre farklı ağırlıklandırılmasını içeren GEM-flex yöntemini geliştirmiştir. Buna göre, bir ülkenin belirli bir makroekonomik gösterge açısından en iyi performansı sağlayabilmesi için söz konusu göstergenin daha fazla ağırlıklandırılması gerekmektedir.

Güran ve Tosun (2005), veri zarflama analizi yardımıyla Türkiye'nin 1951-2003 dönemine ilişkin makroekonomik performansını değerlendirmiştir. Bolotov, Cajka ve Gajduskova (2013), 2008 küresel krizi sırasında Çekya ve Slovakya ekonomilerinde para ve maliye politikalarının etkinliğini araştırmıştır ve her iki ülke ekonomisini Kaldoryan perspektifte karşılaştırmışıır. Kucera (2012), Çekya'nın makroekonomik performansını 2006-2011 dönemi için analiz etmiştir. Firme ve Teixeira (2014), Brezilya, Rusya, Çin, ABD, Euro Bölgesi gibi ekonomilerin ve son sanayileşmiş Asya ekonomilerinin (Hong Kong, Kore, Singapur ve Tayvan) 1997 2012 dönemindeki makroekonomik performansını incelemiştir. Fitoussi ev Saraceno (2013), ABD, Almanya, Fransa ve İtalya'nın makroekonomik performanslarını 1981-1990 ve 1991-2000 dönemleri için karşılaştırmıştır. Urfalığlu ve Genç (2013), çok kriterli karar verme yöntemleriyle Avrupa Birliği ülkeleri ve Avrupa Birliği'ne aday ülkelerin performanslarını karşılaştırmışır. Gress (2014), Ukrayna'nın büyüme performansının istikrarlı olması halinde temel makro ekonomik göstergelerde iyileşme sağlanacağı için OECD'nin tam üyesi olması 
gerektiği sonucuna ulaşmıştır. Chattopadhyay ve Bose (2015), çoklu kriterli karar verme yöntemlerinin bir varyantı olan TOPSIS yöntemini kullanarak ülkelerin makroekonomik performansını karşılaştırmıştır. Rivano ve Teixeira (2017), sosyoekonomik hedefler arasındaki çatışmaların üstesinden gelebilmek için sihirli kare için farklı yaklaşımların kullanılması gerektiğini ifade etmişlerdir. Bu bağlamda, "sihirli hiperküp" olarak adlandırılan yeni bir matematiksel yaklaşım önermişlerdir. Çalışmada, Brezilya ve Şili'den alınan ekonomik veriler kullanılarak yeni konseptin bir uygulaması sunulmuştur.

Ekren, Alp ve Yağmur (2017), gelişmekte olan ülke ekonomilerinde genel ekonomik duruşu daha iyi açıklayabilen bir makroekonomik performans endeksi geliştirmiştir. Çalışmada; Türkiye, Brezilya ve Polonya olmak üzere üç yükselen ekonomiden alınan veriler kullanılmıştır. Picek (2017), Euro Bölgesi ülkeleri için klasik sihirli kare yaklaşımını kullanarak bir makro ekonomik performans endeksi geliştirmiştir. Çalışmada, endeks için dört bileşene eşit ağırlık veren basit bir tek tip ağırlıklandırma şemasının en basit, en izlenebilir ve en yararlı yaklaşım olduğu savunulmaktadır. Wang ve Le (2018), veri zarflama analizi ile gelişmiş ülkelerde ve gelişmekte olan Asya ülkelerinde makroekonomik performans ölçümü ve tahmini gerçekleştirmiştir. Al ve Yıldız (2019), tarafından büyüme, işsizlik, enflasyon ve cari dengeye ilişkin verilerle Türkiye'nin yılllk ekonomik refah endeksleri oluşturulmuş ve bu endeks değerleri yardımıyla Türkiye ekonomisinin makroekonomik performansı değerlendirilmiştir. Daşbaşı, Barak ve Çelik (2019), Türkiye'de 19902017 döneminde makroekonomik performans endeksi işsizlik, enflasyon, büyüme, cari açık ve bütçe açığı değişkenlerine ait verilerle Yapay Sinir Ağı yöntemiyle tahmin etmişlerdir. Ela ve Kurt (2019), TOPSIS yöntemini kullanarak Sahra Altı Afrika ülkelerinde büyüme oranı, enflasyon oranı, işsizlik oranı ve cari işlemler dengesi değişkenlerini kullanarak karşılaştırma yapmışlardır.

Christou, Philippopoulos ve Vassilatos (2020), 12 Euro Bölgesi ülkenin makroekonomik performans asimetrilerinin nedeni olarak kurumlara işaret etmektedir. Orhan (2020), çok kriterli karar verme yöntemlerinden birisi olan ARAS yöntemiyle Avrupa Birliği ülkeleri ile aday ülkelerin makroekonomik performansını karşılaştırmıştır. Hamamcı ve Şahinoğlu (2020) tarafından, 22 
yükselen piyasa ekonomisinin makroekonomik performans endeksleri hesaplanarak söz konusu endeks üzerinden karşılaştırma yapılmıştır. Bu kapsamda, ele alınan ülkelerin 2000-2017 dönemine ilişkin büyüme, enflasyon, istihdam, bütçe dengesi ve dış ticaret verileri kullanılmıştır. Makroekonomik performans endeksinin hesaplanmasında Temel Bileşenler Analizi yöntemi kullanılmışır. Hamdini ve Gaidi (2021), Cezayir ekonomisi için Kaldoryan perspektifli bir ekonomik istikrar endeksi geliştirmiştir. Ekonomik büyüme, istihdam, genel fiyat seviyesi ve dış denge göstergeleri açısından en iyi sonuçların elde edildiği dönem, ekonomik istikrar endeksinin en yüksek değeri yansıttığı dönem olarak işaretlenmiştir. Deleidi, Meloni, Salvati ve Tosi (2020), İtalyan Kuzey-Güney ayrımını bir Kaldor-Verdoorn perspektifine dayandırmaktadır. Çalışmada, emek üretkenliği, sermaye birikimi ve çıktı artışı arasındaki içsel ilişkiyi değerlendirmek için, panel yapısal vektör otoregresif (P-SVAR) modellemesi, İtalya'nın 1981-2013 verilerine uygulanmıştır.

\section{Metodoloji ve Ampirik Analiz}

\subsection{Ağırlıklandırılmış Endeksler Yöntemi}

Illk aşamada, Melyn ve Moesen (1991) ile Cherchye'in (2001) önerdiği üzere veriler doğrusal normalizasyon yöntemi ile standartlaştırılmıştır. Enflasyon ve işsizlik oranları için en iyi durum minimizasyon formülü kullanılırken; büyüme oranı ve cari işlemler dengesi/GSYH oranları için ise en iyi durum maksimizasyon formülünden yararlanılmıştır. Bunun nedeni, makroekonomik performansın izlenmesinde enflasyon ve işsizlik oranlarının düşmesinin; büyüme oranı ve cari denge/GSYH oranının yükselmesinin olumlu yönde katkı sağlamasıdır. Seriler 0 ile 1 arasında değerler almakta olup, bu değerler bire yaklaştıkça performansın iyiye gittiğini, sıfıra yaklaştıkça performansın kötüleştiğini göstermektedir. Birinci denklem en iyi durum maksimizasyonu, ikinci denklem en iyi durum minimizasyonu temsil etmektedir.

$$
x_{t}^{E}=\frac{x_{t}-x_{\min }}{x_{\max }-x_{\min }}
$$




$$
x_{t}^{E}=\frac{x_{\max }-x_{t}}{x_{\max }-x_{\min }}
$$

$x_{t}^{E}: \mathrm{x}$ değişkeninin normalleştirilmiş değeri

$x_{t}: \quad x$ değişkeninin $t$ zamanındaki değeri

$x_{\text {min }}$ : Tüm veriler içinde değişkenin aldığı minimum değer

$x_{\max }$ : Tüm veriler içinde değişkenin aldığı maksimum değer

İkinci aşamada, sihirli kare formülasyonu içerisinde değişkenlerin ne şekilde ağırlıklandırılacaklarına ilişkin olarak Benlialper ve ark. (2015) tarafından yapılan çalışmaya başvurulmuştur. Söz konusu çalışmada, makroekonomik performans endeksi ve ağırlıklandırmaları 4 ayrı kategoride düzenlenerek dar çekirdek, genişletilmiş çekirdek, Keynesyen ve Boratav-Heterodoks olarak kavramsallaştırılmıştır.

Tablo 1: Makroekonomik Performans Endeksleri ve Ağırlıklandırmalar

\begin{tabular}{|l|c|c|c|c|}
\hline Endeks/Ağırlıklandırma & Enflasyon & İşsizlik & Büyüme & İşlemler Dengesi/GSYH \\
\hline Dar Çekirdek & $1 / 3$ & $1 / 3$ & $1 / 3$ & - \\
\hline Genişletilmiş Çekirdek & $1 / 4$ & $1 / 4$ & $1 / 4$ & $1 / 4$ \\
\hline Keynesyen & $1 / 5$ & $2 / 5$ & $2 / 5$ & - \\
\hline Boratav-Heterodoks & - & $1 / 3$ & $1 / 3$ & $1 / 3$ \\
\hline
\end{tabular}

Kaynak: Benlialper ve ark. (2015) çalışmasından alıntılanmıştır.

Dar çekirdek endeksi; işsizlik, enflasyon ve büyüme oranını eşit olarak ağırlıklandırmayı ifade ederken; genişletilmiş çekirdek endeksi; cari işlemler dengesini de ekleyerek dört değişken için eşit bir ağırlıklandırmayı içermektedir. Keynesyen endekste, işsizlik ve büyüme oranının ağırlığı artııılırken, enflasyon oranının ağırlığı azaltılmıştır. Boratav-Heterodoks endekste ise, enflasyon oranının refah göstergesi olamayacağından hareketle enflasyon oranı dışarıda bırakılarak büyüme, işsizlik ve cari işlemler dengesi eşit olarak ağırlıklandırılmıştır. 
Tablo 2: Normalizasyon Sonuçları

\begin{tabular}{|c|c|c|c|c|c|c|c|c|}
\hline YILLAR & $\begin{array}{c}\text { Enflasyon } \\
\text { Oranı }\end{array}$ & $\begin{array}{l}\text { İşsizlik } \\
\text { Oranı }\end{array}$ & $\begin{array}{c}\text { Büyüme } \\
\text { Oranı }\end{array}$ & $\begin{array}{c}\text { Cari } \\
\text { İşlemler } \\
\text { Dengesi/ } \\
\text { GSYH }\end{array}$ & $\begin{array}{c}\text { Dar } \\
\text { Çekirdek }\end{array}$ & $\begin{array}{c}\text { Genişletilmiş } \\
\text { Çekirdek }\end{array}$ & K & $\begin{array}{l}\text { Boratav- } \\
\text { Heterodoks }\end{array}$ \\
\hline 0 & & & 0,2 & & 8 & & 8 & \\
\hline 1981 & 68351871 & 13043 & 629412 & 807 & 0,741991316 & 95322 & 85838 & 194 \\
\hline 1982 & 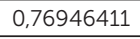 & 0,855072 & 41 & 399 & 5915 & 07 & 277 & 74 \\
\hline 1983 & 近 & & -5 & & & 29 & & \\
\hline 1984 & 49 & 8 & $-5+2>$ & 33 & 94 & 54 & 0,7 & 88 \\
\hline 1985 & 59565 & 6522 & 058 & 899 & 62 & 37942 & 944 & 3705 \\
\hline 1986 & 38 & 58 & 0 & 02 & 1421 & 0,737393774 & 83 & 907 \\
\hline 1987 & 67037412 & 0,782609 & 0,9 & 945 & 0,784327604 & 0,771731941 & 3301 & 8883 \\
\hline 1988 & 36804853 & 695652 & 476471 & 81651 & 0,513390432 & 0,630455668 & 458812 & 4713 \\
\hline 1989 & 年 & LT & 358824 & 083 & - & 0,597927822 & 35 & 009 \\
\hline 1990 & & & 0,00 & & & & & \\
\hline 19 & & & & & & & & \\
\hline 1992 & 4 & & 4 & & & 8 & & \\
\hline 1993 & 334 & 0,652174 & 0,794118 & 6239 & 0,613880132 & 0,581969732 & 0,657586391 & 0,64 \\
\hline 1994 & 0 & 710145 & 0,064706 & 1 & 258283603 & 0,443712702 & 0,309940324 & 16937 \\
\hline 1995 & 1627907 & 55072 & 0,805882 & 88073 & 7915171 & 0,627954727 & 066 & 404 \\
\hline 1996 & 5075834 & 1 & 471 & 48 & 777 & 0,681119159 & 0,7 & 65 \\
\hline 1997 & & & & & & & & 394 \\
\hline 1998 & & & & & & & & \\
\hline 1999 & 40748231 & 0,84058 & 0,147059 & 0,779817 & 46504028 & 0,543734338 & 0,476551875 & 151682 \\
\hline 2000 & 0859454 & 14493 & 74705 & 486239 & 756715372 & 689096162 & 0,8 & 337 \\
\hline 2001 & 5015 & 913 & 0 & 8826 & 29 & 0,560901569 & 204 & 041 \\
\hline 2002 & 60869565 & 0,449275 & 0,717647 & 0,788991 & 0,591872691 & 0,641152225 & 0,588508099 & 1082 \\
\hline 2003 & 9828 & 34783 & 0,682353 & 59633 & 5414461 & 0,639691027 & 0,615 & 5275 \\
\hline 20 & & & & & & 99 & & 5 \\
\hline 2005 & $980 / 8868$ & & 0,870588 & & & 0,678008435 & & 0,577081688 \\
\hline 2006 & 96663296 & & & & & & & \\
\hline 2007 & 97472194 & 66667 & 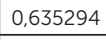 & 21101 & & ,649445911 & 0,71572 & $=110$ \\
\hline 2008 & 5854398 & 50725 & 0,388235 & 348624 & 632501305 & 0,561531942 & 0,567292769 & 595 \\
\hline 2009 & 1 & 0,130435 & 058824 & 66055 & 396419437 & 0,462452193 & 25 & 959 \\
\hline 2010 & $970 / 4419$ & 97 & 4 & 88 & 68 & 0,627853347 & 325 & 564 \\
\hline 2011 & . & 0,681159 & 1 & 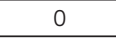 & 0,893045725 & 0,669784294 & 0,872059319 & 0,560386473 \\
\hline 2012 & 97371082 &, 782609 & 62352 & 0,321101 & 0,793282975 & 0,675237461 & 0,757197407 & 0,575746342 \\
\hline 2013 & 98786653 &, 695652 & 0,841176 &, 284404 & 0,841565059 & 0,702274712 & 0,812304764 & 77438 \\
\hline 2014 & ) & 0.52173 & 0,629412 & .440367 & 7002070 & 0,641307172 & 0,655202522 & 56 \\
\hline 2015 & 0,98584429 & 0,478261 & . & 0,522936 & 0,721368386 & 0,671760234 & 0,668473205 & 0,56706555 \\
\hline 2016 & 0,98483316 & 0,391304 & 0,535294 & 53211 & 0,637143877 & 0,610885431 & 0,567606019 & 486236186 \\
\hline 2017 & 0,95146613 & 0,391304 & 0,782353 & 0,385321 & 0,708374472 & 0,627611129 & 0,659756141 & 0,519659463 \\
\hline 2018 & 0,89888777 & 76812 & 0,517647 & 0,568807 & 0,597782139 & 0,590538439 & 0,537561014 & 0,487755331 \\
\hline 2019 & 0,91001011 & 0 & 0,394118 & 0,926606 & 0,434709253 & 0,557683316 & 0,339649081 & 0,440241051 \\
\hline 2020 & 0,91607685 & 0,115942 & 0,447088 & 0,93578 & 0,400869037 & 0,534596732 & 0,297827475 & 0,407436694 \\
\hline
\end{tabular}


Tablo 2'de Dünya Bankası'ndan elde edilen veriler yardımıyla oluşturulan normalizasyon sonuçları dört ayrı kategoride görülmektedir. Endeks değeri sıfır ile bir arasında değerler almıştır. . Endeks değerleri yükseldikçe ekonominin daha iyiye gittiği yönünde bir çıkarımda bulunulabilir. Nitekim kriz dönemlerinde endeks değerlerinde düşüşler yaşanmıştır. Buradan hareketle, Türkiye'nin makroekonomik performansının yıllar itibariyle nasıl bir gelişme gösterdiği aşağıdaki şekilde açıkça görülmektedir. Şekil 1, sırasıyla dar çekirdek, genişletilmiş çekirdek, Keynesyen ve Boratav-Heterodoks endeks değerlerinin yıllar içindeki görünümünü sunmaktadır.

Şekil 1. Endeks Değerlerinin Tüm Kategorilerde 1980-2020 Dönemine İlişkin Trendi

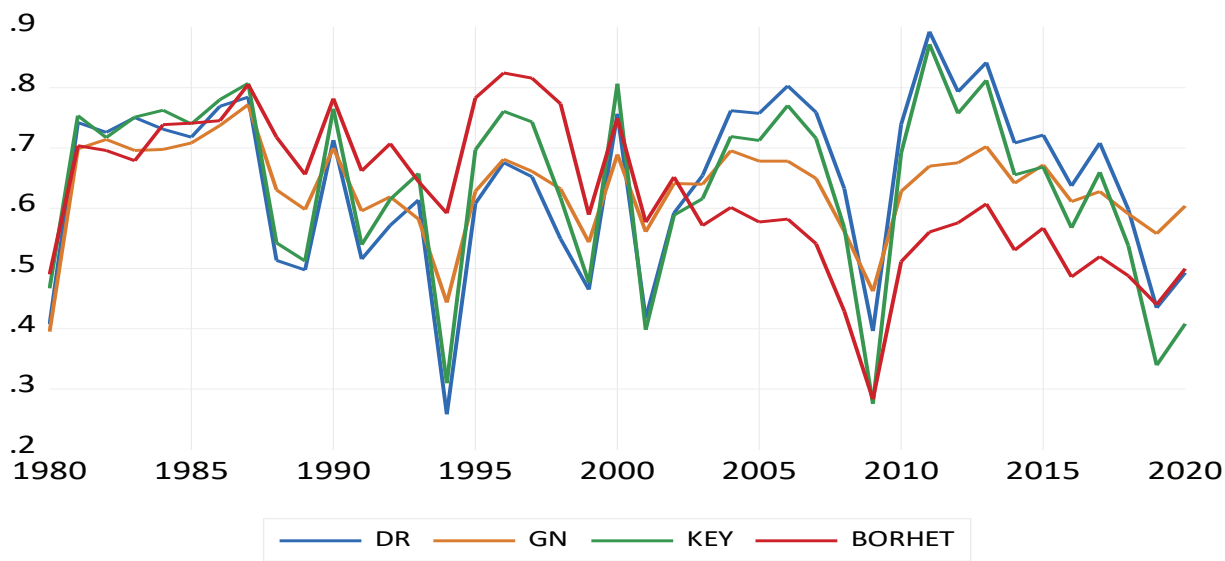

Her dört makroekonomik endeks açısından değişkenlerdeki kırılımlar yıllar itibariyle benzer bir yapı sergilemiştir. Bununla birlikte, Boratav-Heterodoks endeksinin 2000'li yıllara kadar en iyimser, 2000'li yıllardan günümüze kadar en kötümser endeks olduğu görülmektedir. 
Tablo 3: On Yıllık Dönemler Bazında Türkiye Ekonomisinin Görünümü

\begin{tabular}{|l|c|c|c|c|}
\hline & $\begin{array}{c}\text { Ortalama } \\
\text { Enflasyon Oranı } \\
\text { (\%) }\end{array}$ & $\begin{array}{c}\text { Ortalama } \\
\text { Işsizlik Oranı } \\
\text { (\%) }\end{array}$ & $\begin{array}{c}\text { Ortalama } \\
\text { Büyüme Oranı } \\
\text { (\%) }\end{array}$ & $\begin{array}{c}\text { Ortalama } \\
\text { Cari İşlemler } \\
\text { Dengesi/GSYH (\%) }\end{array}$ \\
\hline $\mathbf{1 9 8 0 - 1 9 8 9}$ & 49,14 & 7,69 & 4,11 & $-1,63$ \\
\hline $\mathbf{1 9 9 0 - 1 9 9 9}$ & 77,24 & 7,79 & 4,0 & $-0,75$ \\
\hline $\mathbf{2 0 0 0 - 2 0 0 9}$ & 22,78 & 9,71 & 4,0 & $-2,98$ \\
\hline $\mathbf{2 0 1 0 - 2 0 2 0}$ & 10,28 & 10,46 & 5,32 & $-3,74$ \\
\hline
\end{tabular}

Tablo 4: Dönemler İtibariyle Endekslerin Değerlendirilmesi

\begin{tabular}{|c|c|c|c|c|c|c|c|c|}
\hline & $\begin{array}{l}\text { Ortalama } \\
\text { Enflasyon } \\
\text { Oranı }\end{array}$ & $\begin{array}{l}\text { Ortalama } \\
\text { İşsizlik } \\
\text { Oranı }\end{array}$ & $\begin{array}{l}\text { Ortalama } \\
\text { Büyüme } \\
\text { Oranı }\end{array}$ & $\begin{array}{l}\text { Ortalama } \\
\text { Cari } \\
\text { İşlemler } \\
\text { Dengesi// } \\
\text { GSYH }\end{array}$ & Dar Çekirdek & $\begin{array}{l}\text { Genişletilmiş } \\
\text { Çekirdek }\end{array}$ & Keynesyen & $\begin{array}{l}\text { Boratav- } \\
\text { Heterodoks }\end{array}$ \\
\hline $\begin{array}{l}1980- \\
1989\end{array}$ & 0,5668352 & 0,842029 & 0,582941 & 0,666972 & 0,663935116 & 0,664694457 & 0,6833551 & 0,697314213 \\
\hline $\begin{array}{l}1990- \\
1999\end{array}$ & 0,2827098 & 0,827536 & 0,576471 & 0,747706 & 0,562238876 & 0,608605763 & 0,61814469 & 0,717237747 \\
\hline $\begin{array}{l}2000- \\
2009\end{array}$ & 0,833367 & 0,549275 & 0,576471 & 0,543119 & 0,653037663 & 0,625558064 & 0,61697179 & 0,556288406 \\
\hline $\begin{array}{l}2010- \\
2020\end{array}$ & 0,9597389 & 0,440053 & 0,664171 & 0,473728 & 0,68798759 & 0,634422719 & 0,63363732 & 0,525983977 \\
\hline \multicolumn{9}{|c|}{ Değişkenler ve Endeksler Bazında En İyi Performansın Görüldüğü Dönemler } \\
\hline $\begin{array}{l}1980- \\
1989\end{array}$ & & $\star \star \star \star \star *$ & & & & $\star \star \star \star \star *$ & $\star \star \star \star * \star$ & \\
\hline $\begin{array}{l}1990- \\
1999 \\
\end{array}$ & & & & $\star \star \star \star \star$ & & & & $\star \star \star \star \star *$ \\
\hline \multicolumn{9}{|l|}{$\begin{array}{l}2000- \\
2009\end{array}$} \\
\hline $\begin{array}{l}2010- \\
2020 \\
\end{array}$ & $\star \star \star \star \star$ & &  & & $\star \star \star \star \star$ & & & \\
\hline \multicolumn{9}{|c|}{ Değişkenler ve Endeksler Bazında En Kötü Performansın Görüldüğü Dönemler } \\
\hline $\begin{array}{l}1980- \\
1989\end{array}$ & & & & & & & & \\
\hline $\begin{array}{l}1990- \\
1999\end{array}$ &  & & 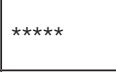 & & $\star * \star * *$ & $\star * \star * \star$ & & \\
\hline $\begin{array}{l}2000- \\
2009\end{array}$ & & & 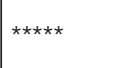 & & & &  & \\
\hline $\begin{array}{l}2010- \\
2020\end{array}$ & & $\star * * * * *$ & & 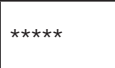 & & & & 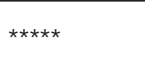 \\
\hline
\end{tabular}

Tablo 3'teki oransal değerler ile Tablo 4'te standart hale getirilmiş değerlerin birbiriyle örtüştüğü görülmektedir. Bu da normalleştirme işleminin minimizasyon ve maksimizasyon kuralları çerçevesinde doğru olarak hesaplandığının göstergesidir. 
Tablo 4, değişkenler ve her dört endeks açısından dönemler boyunca Türkiye'nin makroekonomik performansını göstermektedir. Buna göre, 1980-1989 dönemi Genişletilmiş Çekirdek ve Keynesyen endekslerde en iyi performansın gözlendiği dönemdir. 1990-1999 dönemi, Boratav-Heterodoks endeksine göre en iyi performansı sergilerken, Dar Çekirdek ve Genişletilmiş Çekirdek endeksleri açısından en kötü performansın gözlendiği dönemdir. 2000-2009 dönemi Keynesyen endekste en kötü performansın gözlendiği dönemdir. 2010-2020 dönemi ise Bpratav-Heterodoks endeksinde en kötü performansın izlendiği görülmektedir. Dolayısıyla endeksler, kırılımlar açısından benzer bir trend göstermekle birlikte, hangi dönemde en iyi ya da en kötü performansın izlendiği konusunda uzlaşamamaktadırlar. Bu durumun ortaya çıkmasında, endekslerin içerdiği makroekonomik göstergelerin ağırlığı etkili olmaktadır. Dar Çekirdek endeksi, cari işlemler dengesi/GSYH göstergesini içermediği için cari işlemler dengesinin en kötü olduğu dönem olan 2010-2020 dönemini en iyi performansın gözlemlendiği dönem olarak işaretlemiştir. Diğer taraftan, Boratav-Heterodoks Endeksi, enflasyon oranını içermediği için enflasyonun en düşük olduğu 2010-2020 dönemini en kötü performansın gözlemlendiği dönem olarak hesaplamaktadır.

\subsection{TOPSIS Yöntemi}

TOPSIS, Çok Kriterli Karar Verme (MCDM) problemlerini çözmek için sıklıkla kullanılan bir değerlendirme yöntemidir. Hwang ve Yoon (1981) tarafından geliştirilen TOPSIS yöntemi, pozitif ideal çözümden uzaklığın en aza indirilmesine ve negatif ideal çözümden uzaklığın maksimize edilmesine dayanan alternatifleri değerlendirmek için kullanılan çok kriterli bir çözüm yöntemidir. Diğer deyişle yöntem, alternatifler arasında ideal çözüme en yakın ve idealden sapma gösteren çözüme en uzak alternatifi tercih edebilmeyi mümkün kılar. Bu çalışmada, Türkiye'nin 1980-2020 dönemi alt dönemler itibariyle gruplandırılarak TOPSiS yöntemi ile analiz edilmiştir. Illk aşamada karar matrisi oluşturulur.

$$
X=\left[\begin{array}{cccc}
X_{11} & X_{12} & \cdots & X_{1 n} \\
X_{21} & X_{22} & \cdots & X_{2 n} \\
\vdots & \vdots & \ddots & \vdots \\
X_{m 1} & X_{m 2} & \cdots & X_{m n}
\end{array}\right]
$$


Karar matrisi olarak Tablo 3'te on yıllık dönemler bazında yer alan enflasyon oranı, işsizlik oranı, büyüme oranı ve cari denge/GSYH oranı kullanılmışır. Ardından veriler, aşağıdaki formül yardımıyla normalize edilmiştir. Böylece değişkenler, aynı şekilde ölçeklendirilmiş/standartlaştııılmış olmakta, birbirleriyle karşılaştırılabilir hale gelmektedir.

$$
r_{i j}=\frac{X_{i j}}{\sqrt{\sum_{i=1}^{m} X_{i j}^{2}}} \quad i=1,2, \ldots . m \quad j=1,2, \ldots, n
$$

Tablo 5: Makroekonomik Değişkenlerin Normalize Edilmesi

\begin{tabular}{|l|c|c|c|c|}
\hline DÖNEM & $\begin{array}{c}\text { Ortalama } \\
\text { Enflasyon Oranı } \\
(\%)\end{array}$ & $\begin{array}{c}\text { Ortalama } \\
\text { işsizlik Oranı } \\
\text { (\%) }\end{array}$ & $\begin{array}{c}\text { Ortalama } \\
\text { Büyüme Oranı } \\
\text { (\%) }\end{array}$ & $\begin{array}{c}\text { Ortalama } \\
\text { Cari Isşlemler } \\
\text { Dengesi/GSYH } \\
\text { (\%) }\end{array}$ \\
\hline $\mathbf{1 9 8 0 - 1 9 8 9}$ & 0,517826791 & 0,427542 & 0,467788 & $-0,319133361$ \\
\hline $\mathbf{1 9 9 0 - 1 9 9 9}$ & 0,813938571 & 0,433101 & 0,455268 & $-0,146840503$ \\
\hline $\mathbf{2 0 0 0 - 2 0 0 9}$ & 0,240050759 & 0,539848 & 0,455268 & $-0,583446267$ \\
\hline $\mathbf{2 0 1 0 - 2 0 2 0}$ & 0,108328437 & 0,581546 & 0,605506 & $-0,732244644$ \\
\hline
\end{tabular}

Üçüncü aşamada, normalize edilen veriler eşit şekilde ağırlıklandırılmıştır (wj=0,25).

$$
\begin{gathered}
a_{i j}=w_{j} r_{i j}=w_{j} \frac{x_{i j}}{\sqrt{\sum_{i=1}^{m} x_{i j}^{2}}} \\
A=\left[\begin{array}{cccc}
a_{11} & a_{12} & \cdots & a_{1 n} \\
a_{21} & a_{22} & \cdots & a_{2 n} \\
\vdots & \vdots & \ddots & \vdots \\
a_{m 1} & a_{m 2} & \cdots & a_{m n}
\end{array}\right]
\end{gathered}
$$

Tablo 6: Normalize Edilen Makroekonomik Değişkenlerin Ağırlıklandırılması

\begin{tabular}{|l|c|c|c|c|}
\hline DÖNEM & $\begin{array}{c}\text { Ortalama } \\
\text { Enflasyon Oranı } \\
\text { (\%) }\end{array}$ & $\begin{array}{c}\text { Ortalama } \\
\text { Işsizlik Oranı } \\
\text { (\%) }\end{array}$ & $\begin{array}{c}\text { Ortalama } \\
\text { Büyüme Oranı } \\
\text { (\%) }\end{array}$ & $\begin{array}{c}\text { Ortalama } \\
\text { Cari İşlemler } \\
\text { Dengesi/GSYH (\%) }\end{array}$ \\
\hline $\mathbf{1 9 8 0 - 1 9 8 9}$ & 0,129456698 & 0,106885 & 0,116947 & $-0,07978334$ \\
\hline $\mathbf{1 9 9 0 - 1 9 9 9}$ & 0,203484643 & 0,108275 & 0,113817 & $-0,036710126$ \\
\hline $\mathbf{2 0 0 0 - 2 0 0 9}$ & 0,06001269 & 0,134962 & 0,113817 & $-0,145861567$ \\
\hline $\mathbf{2 0 1 0 - 2 0 2 0}$ & 0,027082109 & 0,145386 & 0,151377 & $-0,183061161$ \\
\hline
\end{tabular}


Dördüncü aşamada, pozitif ve negatif ideal çözümler belirlenmiştir. J fayda kriterlerinin indeks setini, J' ise maliyet kriterlerinin indeks setini tanımlamaktadır Pozitif ve negatif ideal çözümlerin oluşturulması aşamasında, değişkenlerin en ideal değerleri ve en istenmeyen değerleri ayrıştırılmıştır. Bu bağlamda, enflasyon ve işsizlik oranlarının minimum değer alması; büyüme oranı ve cari denge/GSYH oranının yüksek bir değer alması tercih edilmektedir.

$$
\begin{aligned}
& a_{i j}^{+}=\left\{(\max a i j \mid j \in J),\left(\min a i j \mid j \in J^{\prime}\right)\right. \\
& a_{i j}^{-}=\left\{(\min a i j \mid j \in J),\left(\max a i j \mid j \in J^{\prime}\right)\right.
\end{aligned}
$$

Beşinci aşamada, uzaklık değerleri hesaplanır. TOPSIS yönteminde her alternatifin pozitif ideal ve negatif ideal noktalardan sapmasını bulabilmek için Euclidian Uzaklık fonksiyonundan yararlanılır. Bu işlem sonucu elde edilen karar noktalarına ilişkin sapma değerleri ise Pozitif İdeal Ayırım $d_{\mathrm{i}}^{+}$ve Negatif İdeal Ayırım $d_{\mathrm{i}}^{-}$ölçüsü olarak adlandırılır. Burada hesaplanacak $d_{\mathrm{i}}^{+}$ve $d_{\mathrm{I}}^{-}$sayısı alternatif sayısı kadar olacaktır.

$$
d_{\mathrm{i}}^{+}=\left[\sum_{j=1}^{n}\left(a_{i j}-a_{i j}^{+}\right)^{2}\right]^{0,5} \quad d_{\mathrm{i}}^{-}=\left[\sum_{j=1}^{n}\left(a_{i j}-a_{i j}^{-}\right)^{2}\right]^{0,5}
$$

Altıncı aşamada, ideal çözüme göre nıspi yakınlık hesaplanır. Her bir alternatifin ideal çözüme göreli yakınlığının $d_{i}^{*}$ hesaplanmasında ideal ve negatif ideal ayırım ölçülerinden yararlanılır. Burada kullanılan ölçüt negatif ideal ayırım ölçüsünün toplam ayırım ölçüsü içindeki payıdır. İdeal çözüme göreli yakınlık aşağıdaki formül ile hesaplanır (Uzun ve Kazan, 2016, s. 102).

$$
d_{i}^{*}=\frac{d_{\dot{\mathrm{i}}}^{-}}{d_{\mathrm{i}}^{+}+d_{\mathrm{i}}^{-}}
$$

Son aşama, hesaplanan yakınlık değerlerinin büyükten küçüğe doğru sıralanmasını içerir. $d_{i}^{*}$ değerinin 1'e yakınlaşması ideal çözüme yakınsamak anlamına gelir. 


$$
0 \leq d_{i}^{*} \leq 1
$$

Tablo 7: Makroekonomik Değişkenlerin İdeal Değerlerinin Belirlenmesi

\begin{tabular}{|l|c|c|c|}
\hline DÖNEM & $d_{\dot{\mathrm{I}}}^{+}$(İdeal Çözüm) & $d_{\mathrm{I}}^{-}$(Negatif İdeal Çözüm) & $d_{i}^{*}$ \\
\hline $\mathbf{1 9 8 0 - 1 9 8 9}$ & 0,114425 & 0,132812 & 0,533179 \\
\hline $\mathbf{1 9 9 0 - 1 9 9 9}$ & 0,17906 & 0,150983 & 0,455667 \\
\hline $\mathbf{2 0 0 0 - 2 0 0 9}$ & 0,121365 & 0,148582 & 0,546539 \\
\hline $\mathbf{2 0 1 0 - 2 0 2 0}$ & 0,151331 & 0,179055 & 0,543755 \\
\hline
\end{tabular}

TOPSIS yöntemine göre hesaplanan 'nin aldığı en yüksek değer olan 0,546539 ile 2000-2009 dönemi, Türkiye ekonomisinin makroekonomik performansının en yüksek olduğu dönem olarak belirlenmiştir. Makroekonomik performansın en düşük olduğu dönem ise 1990-1999 dönemi olup Dar Çekirdek ve Genişletilmiş Çekirdek endeksleri ile aynı sonuca ulaşılmışırı.

\section{Sonuç}

Uluslararası karşılaştırmalarda kullanılan en temel göstergeler enflasyon oranı, işsizlik oranı, ekonomik büyüme oranı ve cari işlemler dengesidir. Bu bağlamda söz konusu değişkenler, bir endeks çerçevesinde bir araya getirilerek ele alındığında, ülke bazında veya uluslararası karşılaştırmalarda pratik bir bakış açısı sağlamaktadır. Bu çalışmada, ilk kez Kaldor'un (1971) enflasyon oranı, işsizlik oranı, büyüme oranı ve cari işlemler dengesi/GSYH değişkenlerinin bir ekonomideki makroekonomik performansın değerlendirileceğine dair görüşünden yola çıkılarak, 1980-2020 dönemi için Türkiye ekonomisinin performansı değerlendirilmiştir. Bu bağlamda, Benlialper ve ark. (2015) tarafından ele alınan endeksler ve TOPSIS yöntemi çerçevesinde bir analiz yapılmıştır. Endeksler; enflasyon oranı, işsizlik oranı, büyüme oranı ve cari işlemler dengesi/GSYH değişkenlerinin farklı yüzdelerde ağırlıklandırılmasıyla elde edilmiştir. 1980-2020 dönemi için söz konusu değişkenler bağlamında dar çekirdek, genişletilmiş çekirdek, Keynesyen, BoratavHeterodoks endeks değerleri hesaplanarak ve ayrıca TOPSIS yöntemi ile Türkiye ekonomisinde dönemler bazında karşılaştırma yapılmıştır. 
Elde edilen sonuçlara göre; yıllar itibariyle endekslerdeki kırılımların birbirine çok benzer olduğu tespit edilmiştir. Bununla birlikte, en iyi ya da en kötü performansın izlendiği dönemler konusunda uzlaşı sağlanamamıştır. En iyi performans gösteren dönem, Dar Çekirdek Endeksine göre 2010-2020 dönemi olarak işaretlenirken, Genişletilmiş Çekirdek ve Keynesyen Endeks, 1980-1989 dönemine, Boratav-Heterodoks Endeksi ise 1990-1999 dönemine işaret etmektedir. Diğer yandan, TOPSIS yöntemi ile 2000-2009 dönemi en iyi performansın izlendiği dönemdir. En kötü performans gösteren dönem ise, Dar Çekirdek Endeksi, Genişletilmiş Çekirdek Endeksi ve TOPSIS yöntemi açısından 1990-1999 dönemi iken, Keynesyen Endeks 2000-2009 dönemine, BoratavHeterodoks Endeksi 2010-2020 dönemine işaret etmektedir.

Sonuçların farklılığı, endekslerde yer alan değişkenlerin ağırlıklarının birbirinden farklı olmasından kaynaklanmaktadır. Dar Çekirdek endeksi, cari işlemler dengesi/GSYH göstergesini içermediği için cari işlemler dengesinin en kötü olduğu dönem olan 2010-2020 dönemini en iyi performansın gözlemlendiği dönem olarak işaretlemiştir. Diğer taraftan, Boratav-Heterodoks Endeksi, enflasyon oranını içermediği için enflasyonun en düşük olduğu 2010-2020 dönemini en kötü performansın gözlemlendiği dönem olarak hesaplamaktadır. Keynesyen ideolojinin hakim olduğu dönemlerde işsizlik oranlarını düşürmeye yönelik politikalar, Keynesyen ve Boratav-Heterodoks endekslerinin iyiliğini arttıracaktır. Söz konusu sonuçlar, dönemler arası etkinlik karşılaştırmalarında beşeri sermaye, verimlilik, kurumlar ve nüfus gibi unsurların analize dahil edilmesi gerektiğini göstermekte; dolayısıyla bu haliyle Kaldoryan bakış açısının yetersiz kaldığına işaret etmektedir.

\footnotetext{
Hakem Değerlendirmesi: Diş bağımsız.

Çıkar Çatışması: Yazar çıkar çatışması bildirmemiştir.

Finansal Destek: Yazar bu çalışma için finansal destek almadığını beyan etmiştir.

Peer-review: Externally peer-reviewed.

Conflict of Interest: The author has no conflict of interest to declare.

Grant Support: The author declared that this study has received no financial support.
} 


\section{Kaynaklar/References}

Al, İ. ve Yıldız E. B. (2019). Türkiye'nin 2006-2017 dönemi makroekonomik performansı: sihirli kare yaklaşımı. Atatürk Üniversitesi IiBF Dergisi, 33(1), 303-320.

Attfield, C., \& Silverstone, B. (1997). Okun's coefficient: a comment. review of economics and statistics, 79(2), 326-329. https://doi.org/10.1162/003465397556692

Barro, R.J. (1999, February 22). Reagan vs. clinton: who's the economic champ?. Business Week. p.22.

Benlialper A., Cömert H. ve Düzçay G. (2015). 2002 sonrası türkiye ekonomisinin performansı: karşılaştırmalı bir analiz. ERC Working Paper in Economics, 15(4), 1-44.

Bolotov, I., Cajka, R., \& Gajduskova, K. (2013). The economic balance of the czech republic and slovakia during the economic crisis, Prag Economic Papers, 4, 504-523. https://doi.org/10.18267/j.pep.465

Bozgeyik, Y. ve Kutlu, A. (2019). Türkiye'de cari açığın belirleyicileri: 1992-2017 dönemi için ampirik çalışma. Maliye Dergisi, 176, 1-26.

Calmfors L,. \& Driffill J. (1988). Bargaining structure, corporatism and macroeconomic performance, economic Policy, 3(6), 13-61. https://doi.org/10.2307/1344503

Chattopadhyay S., \& Bose S. (2015). Global macroeconomic performance: a comparative study based on composite scores, Journal of Reviews on Global Economics, 4, 51-68. https://pdfs. semanticscholar.org/

Cherchye L. (2001). Using data envelopment analysis to assess macroeconomic policy perfromance, Applied Economics, 33, 407-416. https://doi.org/10.1080/00036840122353

Christou T., Philippopoulos A., \& Vassilatos V. (2020). Institutions and macroeconomic performance: core vs periphery countries in the eurozone, Athens University and Economics and Business Working Paper Series, 9, 1-23. Erişim adresi: https://www.dept.aueb.gr/

Daly, M., \& Hobijn, B. (2010). Okun's law and the unemployment surprise of 2009. FRBSF Economic Letter, 7, 1-5. Erişim adresi: https://www.frbsf.org/

Daşbaşı, B., Barak, D. ve Çelik, T. (2019). Türkiye için makroekonomik performans endeksinin analizi (1990-2017): yapay sinir ağı yaklaşımı. Bingöl Üniversitesi İktisadi ve Idari Bilimler Fakültesi Dergisi, 3(1), 93-112.

Deleidi, M., Meloni, W. P., Salvati, L., \& Tosi, F. (2020). Exploring the determinants of labour productivity growth in italian regions: a kaldorian perspective, ASTRIL Working Paper, 51, 1-29. https://host.uniroma3.it

Dullien S. (2017). A new magic square for inclusive and sustainable economic growth a policy: framework for germany to move beyond gdp, Friedrich Ebert Stiftung, 1-32. Erişim adresi: http://library.fes.de/

Ekren, N., Alp, E. A. ve Yağmur M. H. (2017). Macroeconomic performance index: a new approach to calculation of economic wellbeing. Applied Economics, 49(53), 5462-5476. https://doi.org/10.10 80/00036846.2017.1310996

Ela M. ve Kurt H. S. (2019). Comparison of macroeconomic performances of sub-saharan african countries with topsis method. Gümüşhane Üniversitesi Sosyal Bilimler Enstitüsü Elektronik Dergisi, 10(3), 547-555. 
Erdoğan, S. ve Bozkurt, H. (2009). Türkiye'de cari açığın belirleyicileri: mgarch modelleri ile bir inceleme. Maliye Finans Yazıları, 23(84), 135-172.

Erdoğan, S., Yıldırım, D. Ç., Çevik, N. K. ve Ünal Ö. T. (2019). Okun yasasının geçerliliği: türkiye'den ampirik bulgular. Maliye Dergisi, 177, 70-86.

Firme V., \& Teixeira J.R. (2014). Index of macroeconomic performance for a subset of countries: a kaldorian analysis from the magic square approach focusing on brazilian economy in the period 1997-2012. Panoeconomicus, 5, 527-542. http://dx.doi.org/10.2298/PAN1405527F

FitoussiJ. P., \& Saraceno F. (2013). European economic governance: the berlin-washington consensus, Cambridge Journal of Economics, 37(3), 479-496. http://dx.doi.org/10.1093/CJE/BET003

Gress, M. (2014). Is ukraıne ready for the oecd membershıp?. Actual Problems of Economics, 158, 4049. Erişim adresi: http://www.irbis-nbuv.gov.ua

Güran M. C. ve Tosun M. U. (2005). Türkiye ekonomisinin makro ekonomik performansı: 1951-2003 dönemi için parametrik olmayan bir ölçüm. Ankara Üniversitesi SBF Dergisi, 60(4), 89-115.

Hamamcı E, E. D. ve Şahinoğlu, T. (2020). Temel bileşenler analiziyle yükselen piyasa ekonomilerinin makroekonomik performansı. Journal of Yasar University, 15(60), 728-745.

Hamdini, A., \& Gaidi, K. (2021). Macroeconomic composite index for economic stability: A kaldorian analysis for the algerian economy. Dirassat Journal Economic Issues, 12(1), 697-715. Erişim adresi: http://journals.lagh-univ.dz/index.php/djei/article/view/1121

Hwang, C.L. \& Yoon, K. (1981). Multiple attribute decision making: methods and applications. New York, Springer-Verlag.

Kaldor, N. (1971). Conflicts in national economic objectives, Economic Journal, 81(321), 1-16. https:// doi.org/10.2307/2229754

Kucera L. (2012). Economic performance evaluation - kaldor's magic square. Katedrový Sborník, 1, 80-89. https://is.vstecb.cz/

Lovell C.A. K.. Pastor J. T.,. \& Turner J. A. (1995). Measuring macroeconomic performance in the oecd: a comparison of european and non-european countries, European Journal of Operational Research, 87, 507-518. https://doi.org/10.1016/0377-2217(95)00226-X

Melyn W., \& Moesen W. (1991). Towards a synthetic indicator of macroeconomic performance: unequal weighting when limited Information is available, Public Economics Research Papers, 17, 1-24. Erişim adresi: http://lirias.kuleuven.be

Moesen W., \& Cherchye L. (1998), The macroeconomic performance of nations measurement and perception, Centre for Economic Studies Discussion Paper Series, 98(22), 1-29. http://www.econ. kuleuven.ac.be/

Okun A. M. (1970). The political economy of prosperity. Washington. The Brookings Institution.

Orhan M. (2020). Avrupa birliği ülkeleri ile avrupa birliği üyeliğine aday olan ülkelerin makroekonomik performanslarının aras yöntemi ile kıyaslanması. Journal of Humanities and Tourism Research, 10(1), 115-129. 
Owyang, M. T., \& Sekhposyan, T. (2012). Okun's law over the business cycle: was the great recession all that different?.. Federal Reserve Bank of St. Louis Review, 94(5), 399-418. http://dx.doi.org/ 10.20955/r.94.399-418

Paya M. (2013). Küresel ortamda iktisat politikaları. İstanbul:Türkmen Kitabevi.

Picek, O. (2017). The magic square of economic policy measured by a macroeconomic performance index, New School for Social Research Working Papers, 1702, 1-32. Erişim adresi: http://www. economicpolicyresearch.org/

Rivano, S. N., \& Teixeira J. R. (2017). Magic hypercube and index of welfare and sustainability. Economia, 18(1), 88-97. https://doi.org/10.1016/j.econ.2016.11.001

Tarı R. ve Kumcu F. S. (2005). Türkiye'de istikrarsız büyümenin analizi (1983-2003 dönemi). Kocaeli Üniversitesi Sosyal Bilimler Enstitüsü Dergisi, 9(1), 156-179.

Telatar, E. (2011). Türkiye'de cari açık belirleyicileri ve cari açık-krediler ilişkisi. Bankacılar Dergisi, 78, 22-34.

Turan, T. ve Afsal, M. Ş. (2020). Türkiye'de cari açığın belirleyicileri: ampirik bir analiz. Finans Politik \& Ekonomik Yorumlar, 651, 217-236.

TÜIK (2021, 12 Şubat). İstatistikler. https://www.tuik.gov.tr

Urfalığlu, F. ve Genç, T. (2013). Çok kriterli karar verme teknikleri ile türkiye'nin ekonomik performansının avrupa birliği üye ülkeleri ile karşılaştırılması. Marmara Üniversitesi i.l..B Dergisi, 35(2), 329-360.

Uzun, S. ve Kazan, H. (2016). Çok kriterli karar verme yöntemlerinden ahp, topsıs ve promethee karşılaştırılması: gemi inşada ana makine seçimi uygulaması. Journal of Transportation and Logistics, 1(1), 99-113.

Wang C. N., \& Le A. L. (2018). Measuring the macroeconomic performance among developed countries and asian developing countries: past, present, and future, Sustainability, 10(10), 1-18. https://doi.org/10.3390/su10103664

Worldbank (2021, February10). Databank. https://data.worldbank.org 